\title{
Understanding flood vulnerability of buildings in US: A perspective through claims data
}

\author{
Navya Vishnu ${ }^{a}$, Raulina Wojtkiewicz and Karthik Ramanathan \\ AIR Worldwide, Two Avenue de Lafayette, Boston, MA-02111, USA
}

\begin{abstract}
The National Flood Insurance Program (NFIP) is the largest provider of flood insurance to residential homes and small businesses in the United States for the last 50 years. This study leverages 40 years of data from the NFIP claims dataset to understand which flood hazard and building features influence flood losses. While understanding the importance of building features such as type of occupancy, presence of basement, height or age etc. on flood resistance, the NFIP dataset also allowed us to explore additional characteristics such as the impact of NFIP guidelines and mitigation practices in newer buildings as well as regional variation due to code enforcement. Apart from building vulnerability, the claims also enable a look at which hazard and building features impact contents loss due to flooding. The occupancy of a building, type of flood hazard (surge, riverine, rainfall driven), flood zone and flood regulations compliance are the main drivers of flood vulnerability of both building and contents coverage. Additionally, this claims analysis also highlights the effectiveness of building code enforcement and the need to expand this mitigation and enforcement practices even outside the 100 -year flood plain extent.
\end{abstract}

\section{Background}

Flood risk due to rainfall from tropical and non-tropical systems have been on the rise all over the world in recent years. In the past decade, the United States (US) experienced many record-breaking flood events, with some of the costliest precipitation events on record happening in the last five years (NOAA, 2020). These billion-dollar loss-causing flood events, both from tropical cyclone events (such as 2017 Hurricane Harvey, 2018 Hurricane Florence) and extreme rainfall (2016 Louisiana Floods or 2019 Midwest Floods), are in part due to changing climate as well as more urbanization in the recent years. These costly flood events bring to the forefront, the need to delineate flood risk better as well as to understand how best to mitigate risk from flooding in future.

Catastrophe (CAT) models, such as developed by AIR, can be effective tools to understand both regional flood risk as well as vulnerability of a given structure to different types of flooding. While different validation sources are used for each of the three components (hazard, vulnerability and financial) of a flood model, having flood claims data from past events can be extremely beneficial in validation of all three aspects of the CAT model.

Gradeci et al. (2019) provide a detailed review on studies that utilize flood claims and insured loss data to understand the impact of built and natural environment characteristics on flood losses. The authors report that while many existing studies explore hazard related variables such as precipitation or rainfall intensity when studying these claims, studies focusing on vulnerability of buildings and various building features on flood losses are limited. Moncoulon et al. (2013), Spekkers et al. (2016) and Lee at al. (2018) have explored some building characteristics in their analysis of flood claims in Europe. In the US, flood insurance claims in Texas have also been used to explore impact of flood zone designations, land use, land cover etc. in mitigating or exacerbating flood risk (Blessing et al, 2017; Brody et al., 2018). Recent studies by Cjakwoski et al. (2017), Kousky and Michel-Kerjan (2017) as well as Wing et al. (2020) focusing on a few aspects of what features drive flood losses are some of the few studies utilizing the claims data to assess the flood vulnerability of different buildings in the US.

In the US, the National Flood Insurance Program (NFIP) offered by the Federal Emergency Management Agency (FEMA) is the largest provider of flood insurance. Until recently, NFIP claims and policy data were not publicly available. NFIP has shared their data previously with researchers to understand key aspects of the flood risk in US (Jones et al., 2006; Cjakwoski et al., 2012; FEMA, 2015). Recently, in an effort to further flood risk communication and engage stakeholders and communities at risk of flooding, FEMA published around 2 million

${ }^{a}$ Corresponding author: nvishnu@air-worldwide.com

DOI 10.3311/ FLOODRisk2020.11.14 
flood claims spanning the last 40 years (FEMA, 2019a). This publicly available dataset comprises not just paid claims and existing and past flood policies written by NFIP, but also critical building information that can help understand building vulnerability to floods.

The NFIP program in addition to providing flood insurance, also require the participating communities to adhere to some flood regulation and mitigation practices. These regulations, typically prescribed for areas within the 100-year and 500-year FEMA flood zones, include minimum elevation requirements for structures as well as protection of service and mechanical equipment. Some of the past studies on NFIP have evaluated the effectiveness of these regulations and NFIP policies (Kriesel and Landry, 2004; Jones et al., 2006; Cjakwoski et al., 2012; FEMA, 2015). The NFIP flood claims have also been used to investigate depth-damage relationships for modelling flood damage (Cjakwoski et al., 2017; Wing et al., 2020).

While these studies explore important questions related to flood risk and vulnerability, the understanding of which building features impact flood resistance still remains unclear. The previous studies have either focused just on tropical cyclone or hurricane flood claims or emphasized a small set of building features to explore their impact on flood losses and are limited to building damage from flooding. The large amount of NFIP flood claims, along with relevant building and other exposure features offers a unique new opportunity to answer questions such as impact of basement, number of stories or occupancy on flood vulnerability and losses. In this study, a detailed analysis is offered to characterize flood vulnerability to both structural and non-structural components including contents of a building in terms of how building features impact flood losses.

The following sections of the paper introduce the NFIP dataset used for this analysis and detail the challenges posed in using this large dataset. The analysis methodology is detailed next followed by a discussion of key insights gleaned from this claim analysis. The discussion is rounded off through a series of comparisons of important exposure characteristics such as presence of basement and impact of NFIP regulation and their influence on flood vulnerability.

\section{NFIP claims dataset}

The NFIP claims dataset published through OpenFEMA (FEMA, 2019a) contains paid claims from 1978 to 2018 , totalling to around 2 million data points. While the NFIP dataset consists of mainly residential claims, there are also some small commercial structures insured by NFIP available in the dataset. The paid claims are also reported separately for building, contents as well as any NFIP payment for mitigation measures and increased cost of compliance for future flooding events.

The dataset contains many key exposure characteristics features such as occupancy type, presence of basement, designated FEMA flood zones etc. However, many salient features of the insured property and the flood hazard event are redacted from the public dataset to maintain confidentiality and privacy of data. Among them, the two flood hazard characteristics that are absent include: 1) Flood depth and 2) Flood sub-peril category (e.g. storm surge, inland flooding, hurricane precipitation). Hence, this study relies on a different version of the NFIP data available to authors as part of the Flood Insurance Risk Study (FIRS) sponsored by FEMA (FEMA, 2015). This dataset contains all claims available in OpenFEMA from 1978 to 2012, with the addition of a few more columns such as structure value, flood depth as well as type of flooding. A description of the type of fields available in this dataset is provided in the NFIP Transaction Record Reporting and Planning (TRRP) manual (NFIP, 2015). For confidentiality reasons, any location identifier fields such as address, latitude or longitude of paid out claims were not available from this dataset.

\subsection{Data fields of interest}

The NFIP claims dataset has many fields of interest relating to both policy terms, flood zone proximity information as well as salient building features. The data fields explored in this study along with a brief description are listed in Table 1. The table also notes if the same data field is available in OpenFEMA.

\begin{tabular}{|c|c|c|}
\hline Data Field & Description & $\begin{array}{c}\text { Available in } \\
\text { OpenFEMA? }\end{array}$ \\
\hline Date of Loss & Date of flood loss event & Yes \\
\hline County/City & $\begin{array}{l}\text { County, city or state of } \\
\text { flood claim }\end{array}$ & Yes \\
\hline Flood Depth & $\begin{array}{l}\text { Water depth in feet as } \\
\text { measured from top of } \\
\text { floor above ground }\end{array}$ & No \\
\hline Cause of Loss & $\begin{array}{c}\text { Type of flooding per } \\
\text { NFIP }\end{array}$ & No \\
\hline Occupancy Type & $\begin{array}{l}\text { Use of building, e.g., } \\
\text { residential or } \\
\text { commercial }\end{array}$ & Yes \\
\hline $\begin{array}{c}\text { Presence of } \\
\text { basement/enclosure }\end{array}$ & $\begin{array}{c}\text { Indication of basement } \\
\text { or enclosure space such } \\
\text { as crawlspace }\end{array}$ & Yes \\
\hline FEMA flood zone & $\begin{array}{c}\text { Flood zone as } \\
\text { designated by FEMA } \\
\text { and FIRM } \\
\end{array}$ & Yes \\
\hline No. of floors & $\begin{array}{c}\text { Number of stories in a } \\
\text { building }\end{array}$ & Yes \\
\hline Post-FIRM indicator & $\begin{array}{c}\text { Indicator if building } \\
\text { was built after FIRM } \\
\text { adoption } \\
\end{array}$ & Yes \\
\hline $\begin{array}{l}\text { Actual Flood } \\
\text { Damage }\end{array}$ & $\begin{array}{l}\text { Actual dollar value of } \\
\text { flood damage }\end{array}$ & No \\
\hline $\begin{array}{l}\text { Amount paid on } \\
\text { claim }\end{array}$ & $\begin{array}{l}\text { The amount NFIP paid } \\
\text { for the same claim }\end{array}$ & Yes \\
\hline Property Value & $\begin{array}{l}\text { The total replacement } \\
\text { value or property value }\end{array}$ & No \\
\hline NFIP Policy Limit & $\begin{array}{l}\text { The maximum coverage } \\
\text { limit for NFIP insurance }\end{array}$ & Yes \\
\hline
\end{tabular}

Table 1. Key data fields from NFIP dataset 


\subsection{Data clean-up and augmentation}

Even though the NFIP dataset contains many fields of interest as noted in Table 1, the information contained in all the fields are often incomplete or erroneous. For example, replacement values of building or contents are often not reported or are reported as zero or very large numbers. In around $18 \%$ of the data, no building replacement values were reported. For residential properties, the NFIP has a maximum limit of $\$ 250,000$ on building and $\$ 100,000$ on contents for most of their insured policies; however, the dataset had reported claims with coverage more than these maximum values. The NFIP TRRP manual (NFIP, 2015) reports that negative water depths are reported in cases where buildings with basements experience flooding only in basements. However, the NFIP dataset contains many cases where a negative water depth has been recorded for buildings without a basement. Such cases along with zero replacement or clearly erroneous fields were removed from the analysis.

In addition to the data clean-up, some data augmentation was done to supplement flood loss information. Based on the date and location of loss, the NFIP claims were attributed to possible flood events and cause of flooding. More details on this process carried out by AIR researchers can be found in AIR Worldwide (2020b). The AIR attributed flood loss event allows further disaggregation of the flood claims into flood losses caused due to 1) storm surge, 2) storm induced precipitation flood, and 3) all other forms of inland flooding. These observations along with other results are presented in following sections.

\section{Claims analysis and methods}

The NFIP claims data are analysed using two main methods: 1) number of claims 2) relationship of flood depth to flood losses. These two different methods offer two views to flood risk- number of claims relates to frequency of flooding events/insured losses and the flood depth to loss relationship analysis provides insights on flood vulnerability of the structure. All the analysis are comparisons in this study are performed using the data visualization and analysis packages in $\mathrm{R}$.

\subsection{Loss metrics for comparison}

For investigating impact of different natural or building features on flood vulnerability, comparison of flood depth to loss trends for different cases have to be carried out. However, since the claims span around 40 years, the value of claim experienced 20 years ago is not the same as the claim experienced today due to year over year inflation or change in wealth. In order to provide a true comparison of flood loss over the years, a loss ratio/damage ratio is used as shown in Equation 1. The loss ratio expresses flood loss as a percentage of the replacement value of building or contents.

$$
\text { Loss Ratio }=\frac{\text { Total Flood Loss }}{\text { Total Replacement Value }}
$$

The loss ratio can be calculated using either actual damage to replacement or by using NFIP payment to NFIP coverage. The former is referred to as a ground-up loss ratio in insurance terms and the latter referred to as insured loss. The loss ratio can also be computed for building damage, contents coverage or total damage or NFIP coverage. The building damage or coverage considered by NFIP and in this study include the building envelope, all permanent fixtures as well as service equipment such as plumbing, electrical and mechanical units. The contents coverage includes all personal belongings as well as movable appliances or equipment (NFIP, 2020). (a)

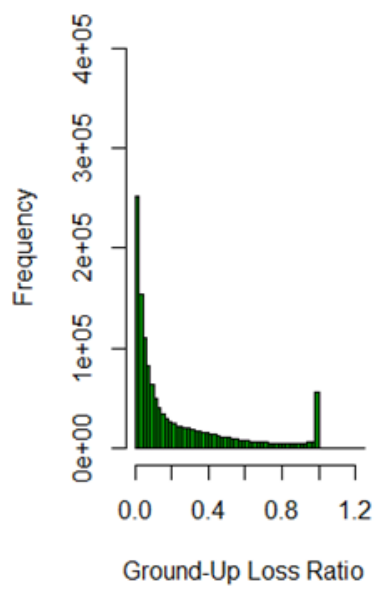

(b)

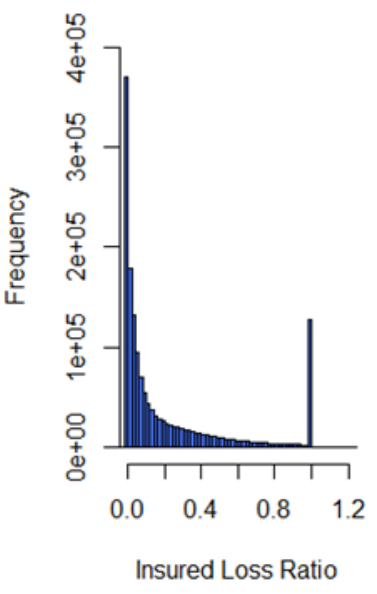

Figure 1. Building loss ratio distribution from NFIP claims for single family residential homes: (a) Ground-up loss ratio and (b) Insured loss ratio

Figure 1 shows the distribution of building loss ratios for ground-up and insured cases, computed for single family residential homes. As expected, maximum value of the loss ratio is 1 when the total flood damage was equivalent to building replacement or when NFIP payment was equivalent to the insurance coverage limit. From the insured loss ratio (NFIP payment to coverage ratio) distribution in Figure 1, it can also be observed that there are a large number of claims where the loss ratio is 1 . This can happen in flooding scenarios where the actual flood damage was more than the NFIP building coverage of $\$ 250,000$; but NFIP payments are limited to the coverage amount. Both loss ratios can reveal different insights to the claims study, with the insured loss ratio being more beneficial in understanding losses incurred by NFIP. The ground-up loss ratio or actual damage to replacement ratio reveals flood losses actually incurred to the property and can be more beneficial for understanding impact of other features on flooding. Hence in this study, the loss ratio adopted for all comparisons are the damage to replacement value. 


\subsection{Uncertainty estimation}

In order to understand influence of natural or built environment on flood loss ratio, a depth-damage relationship is used. However, due to the large size of the data and inherent variability, for every case studied in this paper, for a given flood depth, there is a large variation of possible loss ratio. This could be partly due to a "dimensionality reduction" issue- wherein the analysis of depth as the only predictor for loss ratio or damage does not reveal the complete picture. The variation could also be caused by inherent uncertainty in predicting nature of flood vulnerability or due to possible data inaccuracies. In any case, using just a mean value to represent depthdamage might be misleading for any insights we glean from this study. Hence, a boxplot depicting mean loss ratio, $25^{\text {th }}$ and $75^{\text {th }}$ percentiles of data as well as outliers for each depth bin as shown in Figure 2 is used for all analysis in this study.

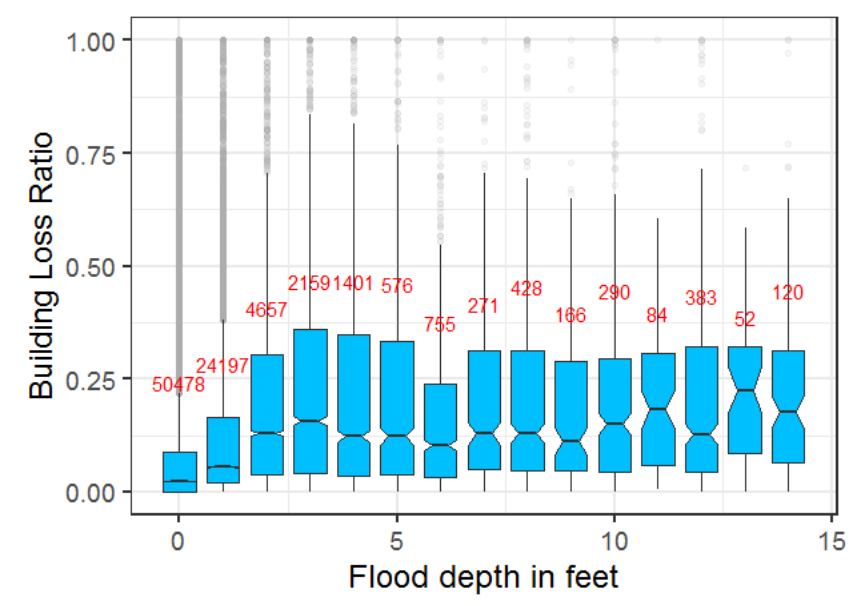

Figure 2. Depth-loss ratio distribution and statistics for residential flood claims in Louisiana

Flood claims for single family residential homes in Louisiana are plotted as a relationship between building loss ratio and flood depth in Figure 2. NFIP reports the flood depth in feet as measured from the top of the first floor above ground. As can be observed, the loss ratios are in bins of integer values of flood depth, indicating that the flood depth in the NFIP dataset is a rounded-off value. Hence, the loss ratio depicted at (say) 5 feet could be a result of a flood depth of 4.8 feet or even 5.2 feet, possibly resulting in large variation of data. The boxplot has a notch indicating the median value with the edges corresponding to the $25^{\text {th }}$ and the $75^{\text {th }}$ percentiles of the loss ratio for each depth bin. The whiskers extend till the 95\% confidence interval of the data in each depth bin and any data points beyond that are represented (in grey) as outliers. In addition, the number of claims available for each depth bin (in red) give more insight into the data distribution. The shorter length of the box, as seen at lower flood depths, suggest less variation in the data and hence the $25^{\text {th }}$ and $75^{\text {th }}$ percentiles are closer to the median. Beyond flood depth of 10 feet, the number of claims available for each depth bin reduces and the data variability also seems high. Hence, all further analysis shown in this study restrict the flood depth study range to be less than 10 feet. The non- linearity of depth to median loss ratio relationship depicted in Figure 2 leads one to question using depth-loss ratio relationship for the analysis. However, when different building or natural features are introduced as predictors of damage or loss, this relationship gets modified as demonstrated in the following sections.

\section{Impact of flood hazard features on vulnerability of building}

This section explores the impact of flood hazard features such as type of flooding, proximity to flood zone as well as regional variation of the claims loss ratio distribution for the building coverage. Depending on the location of a building, the type of flood causing damage can be storm surge induced flooding, riverine flooding or urban/off-street flooding. The state and flood zone can also have an impact in local flood mitigation practices and protections that are not individual building specific considerations. For simplicity, all claims analysed in this section are for single family homes without a basement and focus on building coverage loss ratio (building envelope, service equipment and permanent fixtures).

\subsection{Type of flooding}

The resistance of a building envelope to flooding can depend on not only the building characteristics, but also on the nature of flooding itself. Coastal storm surge flooding, as seen during Hurricane Katrina in 2005, can be devastating largely owing to the increased velocity of water flow. In contrast, urban flooding or street flooding due to extreme precipitation usually sees water levels rising gradually with minimal velocity or flow. Riverine flooding can sometimes have significant flow velocity and can also affect the structure for longer duration. In addition, the precipitation induced flooding usually has lower flood depths and riverine as well as storm surge induced flooding can result in larger flood depths, depending on the event.

As described in Table 1, NFIP claims contain a data field called "Cause of Loss" for each flood claim. The NFIP TRRP manual (NFIP, 2015) describes the Cause of Loss in detail and the main types of flooding are:

- tidal overflow corresponding to coastal flooding cases

- $\quad$ stream or riverine overflow corresponding to inland flooding cases

- flooding due to accumulation of rainfall

- all other types of flood damage including erosion, landslide etc.

Figure 3 shows the depth to building loss ratio distribution of the three main types of flooding classified based on NFIP- 1) coastal storm surge, 2) precipitation or rainfall induced flooding and 3 ) riverine and stream overflow.

The trends in Figure 3 are unexpected since there is no significant distinction between loss ratios due to type of flooding any flood depth. One of the main differences observed is the lower loss ratio (and damage potential) for inland flooding at higher depths of 8 or 9 feet; however due to large variation in loss ratio at these depths, no 
definitive comparisons can be made. The NFIP assigned cause of loss may not give complete information especially in cases of expedited claim settlement when site inspections are not conducted. So, to further investigate this, instead of using NFIP's cause of loss, the flood event type assigned by AIR is used to evaluate the relative damage potential of flooding cause. As mentioned in Section 2.2, as part of data-augmentation, AIR assigned flood events 1) storm surge, 2) storm induced precipitation flood, and 3) all other forms of flooding. Figure 4 shows the depth- building loss ratio distribution by AIR assigned flooding cause.

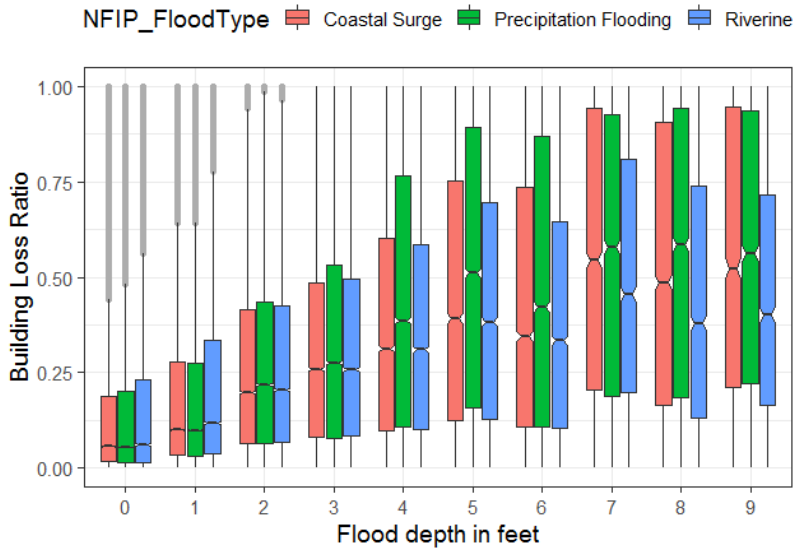

Figure 3. Depth-loss ratio distribution of residential homes without basement by different cause of loss assigned by NFIP

AIR_FloodType 帛 Coastal Surge Precipitation 후 Riverine and other

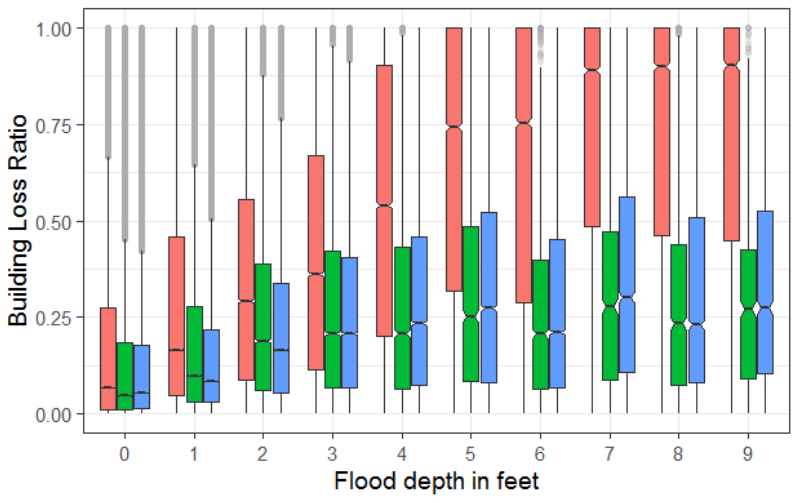

Figure 4. Depth-loss ratio distribution of residential homes without basement for different flooding types assigned by AIR

Figure 4 shows a distinctive pattern in contrast to Figure 3, where surge related flooding shows larger loss ratio at each depth bin. Additionally, the relative mean loss ratio for inland flood and precipitation flooding reveals some trends. At lower flood depths, the mean loss ratios are closer and at higher flood depths, inland flooding type events have slightly higher loss ratios. This follows engineering intuition as at lower depths, inland flooding has lower or no flow velocity similar to precipitation flooding and exhibits similar damage potential. Even though Figure 4 shows surge to have much higher damage potential, it is important to note that the around half of the surge claims in the NFIP dataset are from the 2005 Hurricane Katrina event. Since Hurricane Katrina had severe storm surge and additional flooding due to failure of levees in Louisiana, the flooding impact from this single event might have different signature from other surge flooding scenarios. Figure 5 shows the depth to building loss ratio by AIR assigned flood type without Katrina losses. After removal of Katrina, the surge loss ratios are more comparable to the other two types of flooding, but the median loss ratio due to surge remains slightly higher than other forms of flooding at lower flood depths.

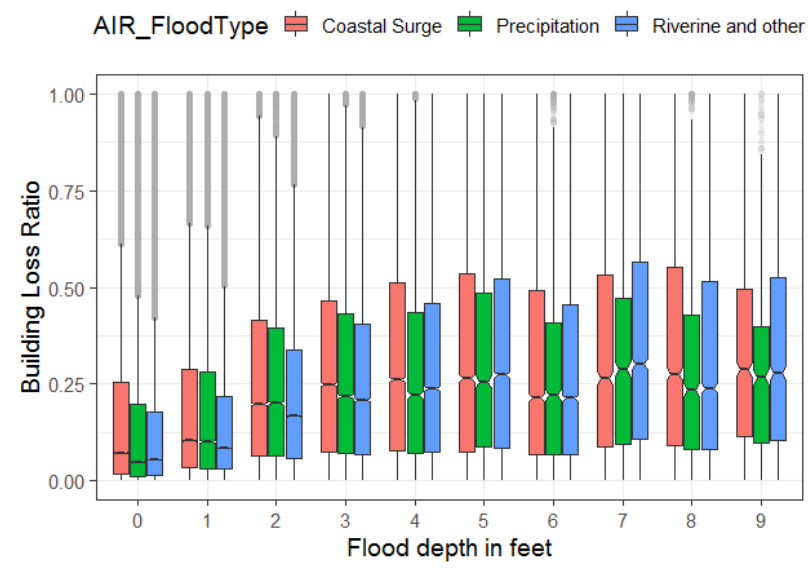

Figure 5. Depth-loss ratio distribution (without Hurricane Katrina) of residential homes without basement for different AIR flooding type

\subsection{FEMA flood zone}

NFIP claims also contain information regarding the flood zones delineated by FEMA. These flood zones are based on flood hazard maps and risk perception of flooding. While FEMA designated flood zones are many, these can be primarily classified under the following types:

- V zone: Coastal Special Flood Hazard Area (SFHA) within the 100-year base flood elevation footprint subjected to high velocity flooding and possible flood hazard due to storm waves.

- A zone: SFHA which falls under the 100-year base flood elevation footprint.

- X, B, C zones: Areas outside the 100-year floodplain with moderate to low flood risk.

FEMA $\mathrm{V}$ and A flood zones have higher flood risk and might have some mandatory flood insurance guidelines in place in some regions. For those areas within zones A and $\mathrm{V}$ where adoption of building standards and flood regulations are good, the more recent structures built inside these flood zones are also subject to more stringent regulations on minimum floor elevation as per the American Society of Civil Engineers (ASCE) Flood Resistant Construction and Design Standard 24-14 (ASCE/SEI, 2015).

Figure 6 shows the building loss ratio distribution of NFIP claims by flood zone $\mathrm{V}, \mathrm{A}$ as well as $\mathrm{X}$ and other non-AV zones. The $\mathrm{V}$ zone and $\mathrm{A}$ zone are further differentiated by FEMA into granular risk zones; however, this level of granularity is not considered in this study. Similarly, the X and other flood zone category in Figure 6 contains all non- $\mathrm{V}$ and non-A zone claims for simplicity.. The mean flood damage ratio in A exceeds both $\mathrm{V}$ and non-AV zones; this could be due to more hazard awareness in $\mathrm{V}$ zones (leading to more mitigation) and less flooding 
instances in non-AV zones. The year-wise distribution of NFIP flood claims by flood zone is shown in Figure 7. The flood claims in $\mathrm{V}$ zones are only $3 \%$ of total claims with close to $69 \%$ of claims coming from A zones, with many years seeing minimal $\mathrm{V}$ zone claims in Figure 7. Even though $\mathrm{X}$ and non-AV zones lie beyond the 100-year FEMA flood footprint, flood claims from these zones make up a third or more of total flood claims every year. In more recent flooding events in US, such as 2017 Hurricane Harvey or 2017 California Flooding have seen a lot more street flooding due to rainfall outside the A and $\mathrm{V}$ zones. This shows a need to re-evaluate flood mitigation strategies beyond just $\mathrm{A}$ and $\mathrm{V}$ zones.

FloodZone 官 A 追 $\mathrm{v}$ 官 $\mathrm{x}$ and others

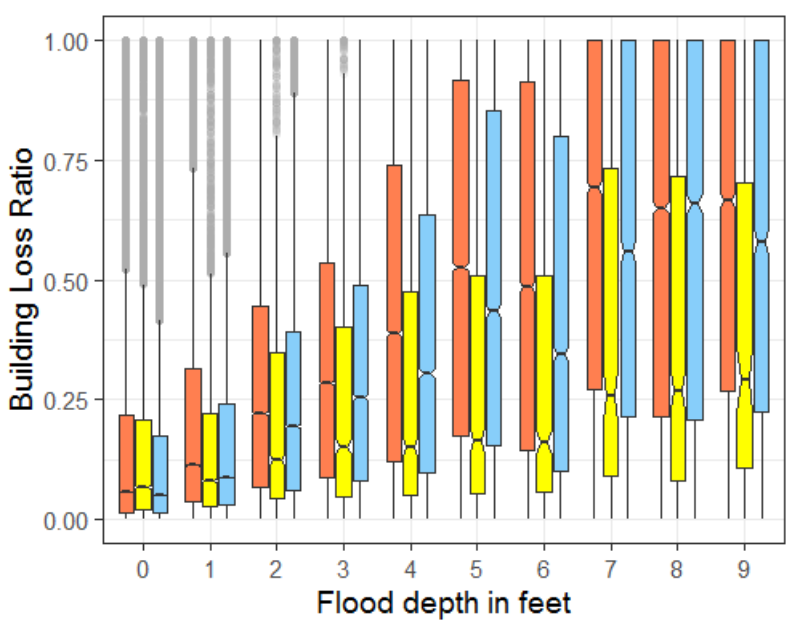

Figure 6. Depth-loss ratio distribution of residential homes without basement for different flood zones

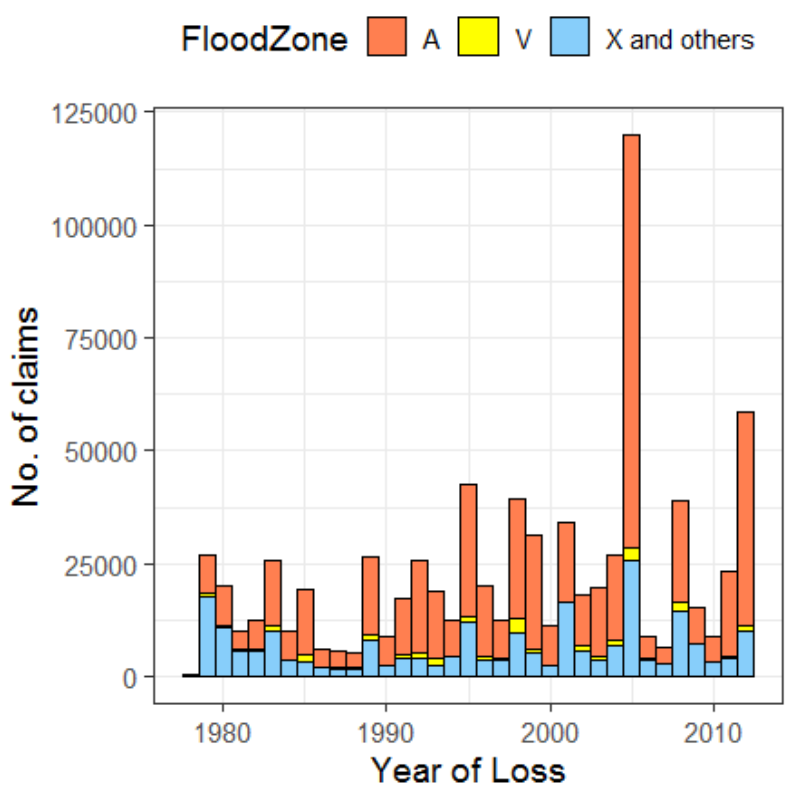

Figure 7. NFIP residential claims (without a basement) over the years classified by different flood zones

\subsection{Claims regional variation}

Building characteristics, construction practices and styles vary according to the state or region in the US. For example, the residential buildings in north-eastern or upper mid-eastern parts of the country are generally older and majority of them are founded on basements. While most single-family residential homes in US are built of wood, masonry buildings are also popular in states such as Florida (FL). In addition to the prevalent construction style and mix, different states have sometimes imposed their own regulations on building practices, such as stringent hurricane mitigation practices in Florida or stringent earthquake mitigation standards in California (CA). Moreover, different parts of the US also experience different types of flooding, with coastal surge flooding or hurricane precipitation related flooding common in the southern coast and Gulf of Texas coast and riverine flooding is common along the Mississippi river in the midwestern states. Hence, a regional variability of claims as shown in Figure 8 can be insightful. The states with maximum number of claims, Louisiana (LA), Texas (TX), FL, New York (NY), New Jersey (NJ), North Carolina (NC) etc. are along the Atlantic coast and the Gulf of Mexico coast with prominent hurricane or storm induced flooding risk. Among the non-hurricane states, CA and mid-western states such as Illinois (IL), Missouri (MO) also have significant flooding history.

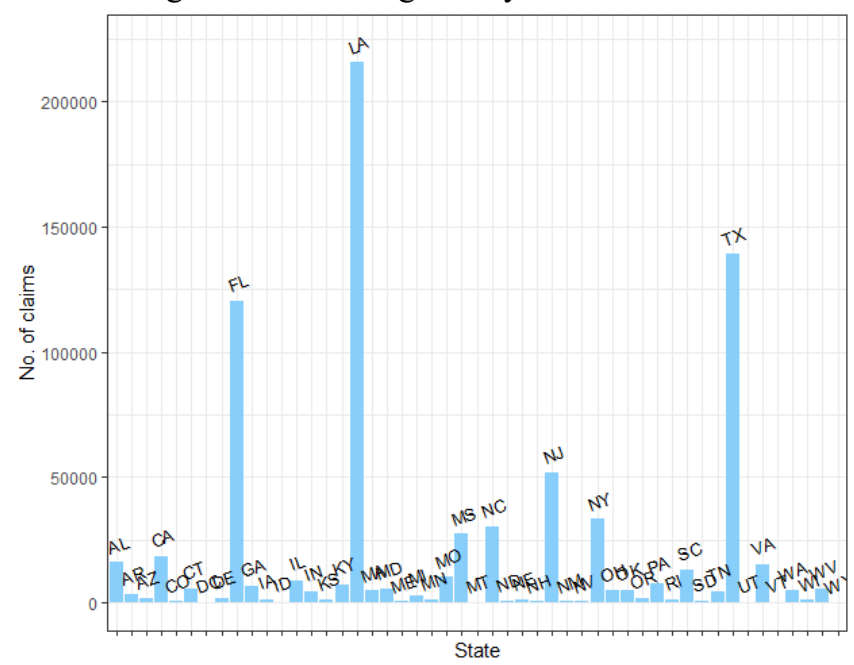

Figure 8. NFIP residential claims (without a basement) distribution by state

Claims from six states- CA, FL, IL, LA, NJ and TXare selected to evaluate depth to building ratio relationship as shown in Figure 9. A few interesting trends are revealed, building loss ratios in CA and FL are lower than the other states at lower flood depths and have small uncertainties around their median loss ratio. Flood losses in both CA and FL are more due to urban flooding, either from smaller stream overflow or extreme precipitation, leading to many instances of flooding with low depths of water. Additionally, as mentioned above, both these states have more stringent building regulations, resulting in a more flood-resistant building envelope. Median loss ratio in TX is greater than all other states at most flood depth bins in Figure 9, except LA. TX has a lot of flooding history, but 
the building code enforcement in TX is not as effective as FL. Loss ratios for IL and NJ are in between FL and TX for most depth bins, mostly attributed to riverine flooding.

As for LA, the uncertainty around the median loss ratio is very high at all depth bins and the trend of depth to loss ratio looks very similar to the surge flooding case observed in Figure 4. This is due to the fact that the flood claims in LA are dominated by the 2005 Hurricane Katrina surge flooding. Similarly, the majority of flood claims in NJ are from the 2012 Hurricane Sandy surge. Figure 10 compares the building ratios from these states after removing all surge claims. The distribution of loss ratios looks different for states with any surge losses- FL, LA, NJ and TX. From Figure 10, it can be observed that LA and TX have very similar loss ratio distribution, which is unsurprising given similar construction mix and building codes in the US Gulf coast. After removing surge losses, median FL loss ratios due to flooding are lower than all other states at every flood depth, reinforcing the importance of flood mitigation practices via building codes. The differences in local flood mitigation planning and the impact of these in lowering flood risk in FL as compared to LA and/or TX is also noted by other studies such as Brody et al. (2010) and Tonn and Czajkowski (2018).

$$
\text { State 追 } \mathrm{CA} \text { 帛 } \mathrm{IL} \text { 官 } \mathrm{NJ}
$$

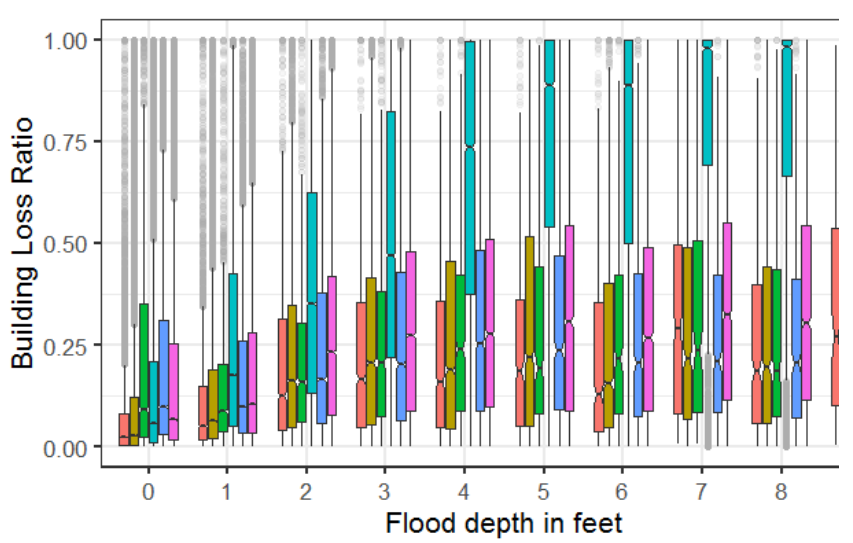

Figure 9. State-wise depth- loss ratio distribution of residential claims without a basement

$$
\text { State 帛 } \mathrm{CA} \text { 章 } \mathrm{IL} \text { 早 } \mathrm{NJ}
$$

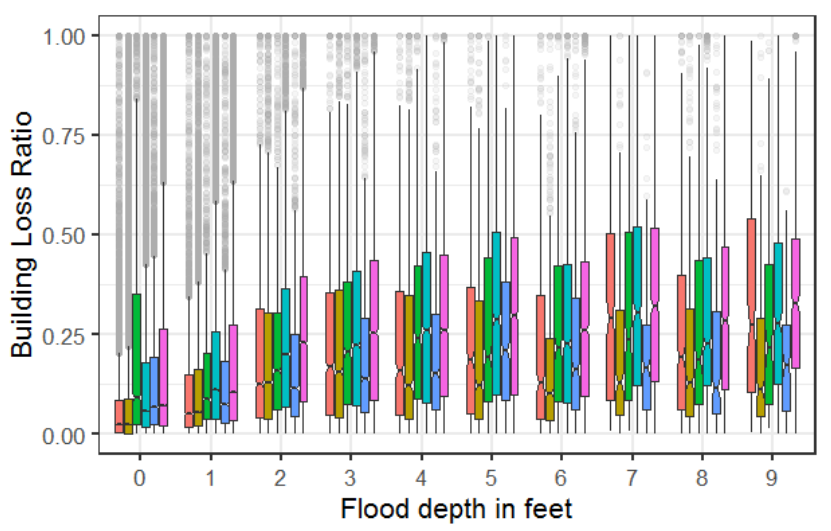

Figure 10. State-wise depth- loss ratio distribution of non-surge residential claims without a basement from NFIP

\section{Impact of building features on its flood vulnerability}

The previous section explored the impact of claim location on building loss ratio distribution for single family residential homes without a basement. However, the flood damage to a building can also be influenced by other building characteristics such as use or occupancy type of building, whether the building has a basement, height (or number of stories) of building as well as whether the building complies with NFIP guidelines for minimum elevation. This section focuses on these building characteristics on flood resistance of a building envelope through claims analysis and comparison. As seen above, type of flooding and flood zone can have significant impact on the depth-loss ratio; hence only non-surge related flood claims within the A zone are used in this section. This allows for interpretation of relativities between loss ratios for different building features without any location bias.

\subsection{Occupancy type}

NFIP largely insures residential properties and as such the flood claims are also comprised of mainly residential flood claims as seen in Figure 11. However, the figure also shows that there is a small percentage of NFIP flood claims from small commercial buildings and small business units. The dataset contains a field called "occupancy" which defines the following building use types:

1. single family homes (SFH)

2. multi-family homes (MFH)

3. other residential (OR)

4. commercial buildings $(\mathrm{C})$

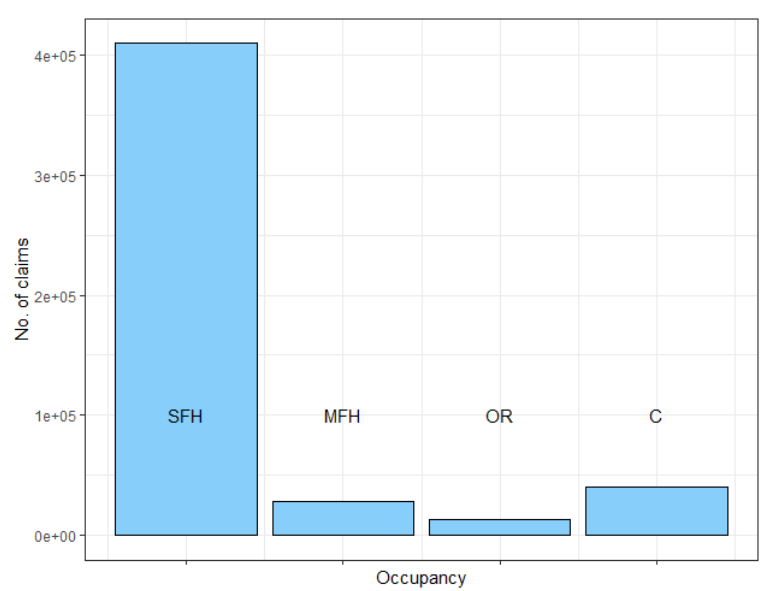

Figure 11. Number of non-surge NFIP flood claims in A zone by occupancy or use type of buildings

In the US, the majority of single-family residential buildings are built of wood or masonry and are typically non-engineered buildings. In contrast, commercial buildings often are engineered and may be built of reinforced concrete or steel. This difference in construction method and material introduces variation in flood vulnerability of these buildings. Wood and masonry are more vulnerable to flood damage and this results in the higher loss ratio for SFH at all depths as seen in Figure 12. 
From the figure, MFH also have higher loss ratios than commercial as these also tend to be low-rise wood buildings. In contrast, the "other residential" buildings have lower median loss ratios than all other occupancies. The latter occupancy type captures residential structures such as apartment buildings which also are typically more engineered.

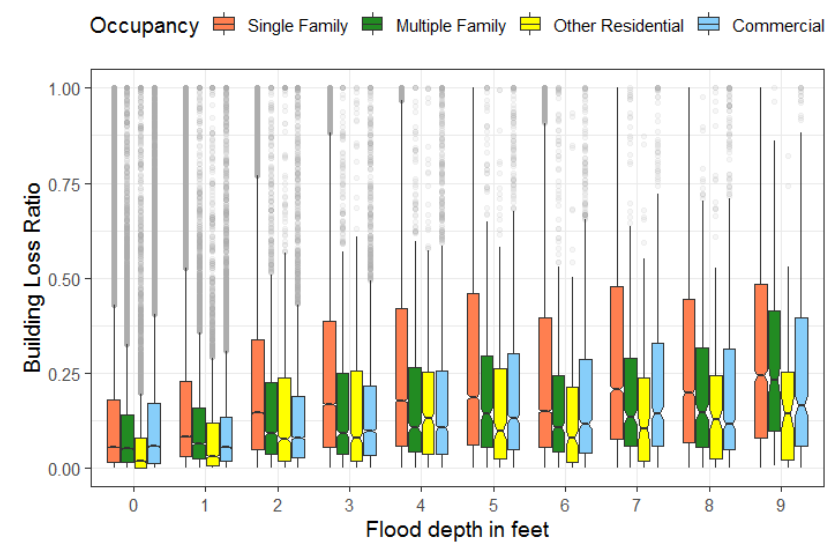

Figure 12. Occupancy-wise distribution of non-surge flood claims in A zone

\subsection{Post-FIRM construction}

NFIP claims contain a field indicating if a building is post-FIRM construction; this indicates if the building was constructed after the implementation of community level Flood Insurance Rate Map (FIRM). This first FIRM was adopted around 1974 and the NFIP claims dataset classifies buildings constructed after 1974 or the initial FIRM adoption year specific to the location to be postFIRM and others to be pre-FIRM. This field, in addition to indicating age of building, also indicate whether a building may have adhered to NFIP guidelines. Compliance of NFIP guidelines is more common for post-FIRM buildings in SFHAs (mainly V and A zones), and rarer outside A and $\mathrm{V}$ zones. NFIP guidelines include elevating lowest floor to be above base flood elevation (BFE) with a freeboard in some cases, removal of obstructions below the main building and moving service equipment to a higher elevation within the building. Post-FIRM construction also has seen a large decrease in buildings built with basements, especially in the A and V zones (AIR Worldwide, 2020a).

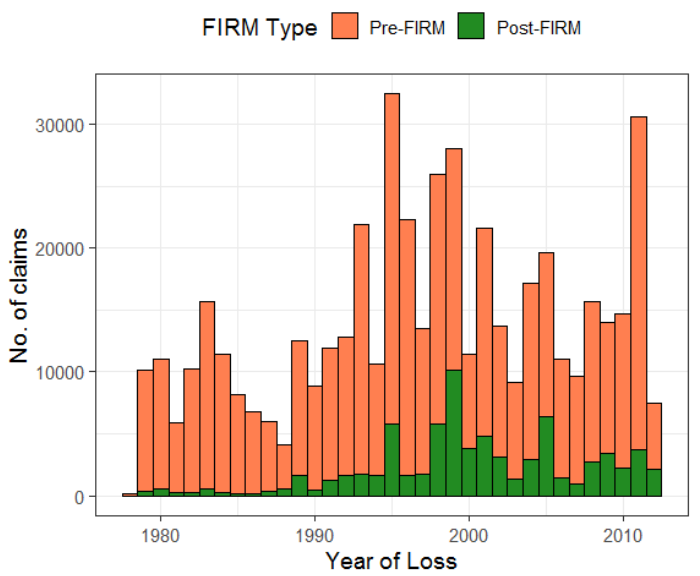

Figure 13. Distribution of non-surge flood claims in A zone over the years by FIRM construction
The yearly variation of flood claims by pre-FIRM and post-FIRM construction within the FEMA Flood Zone A is shown in Figure 13. As aforementioned, FIRM was first established around 1974 and most of the flood claims around that year and immediately constitute of pre-FIRM buildings. Once FIRM and NFIP guideline compliance was more in place, the distribution of flood-affected buildings change; however, majority of flood claims within the A zone comprise of pre-FIRM buildings. The depth to loss ratio distribution of these buildings by different FIRM type is shown in Figure 14. As expected, the post-FIRM buildings suffered lower flood loss ratios for similar depths for almost all depth bins. This is largely due to elevated construction and movement of service equipment. Similar observations of effectiveness of NFIP guideline compliance in lowering flood losses is also observed in FEMA (2015) report as well as various FEMA mitigation assessment team reports after major flood events (FEMA 2009a, FEMA 2009b, FEMA 2019b).

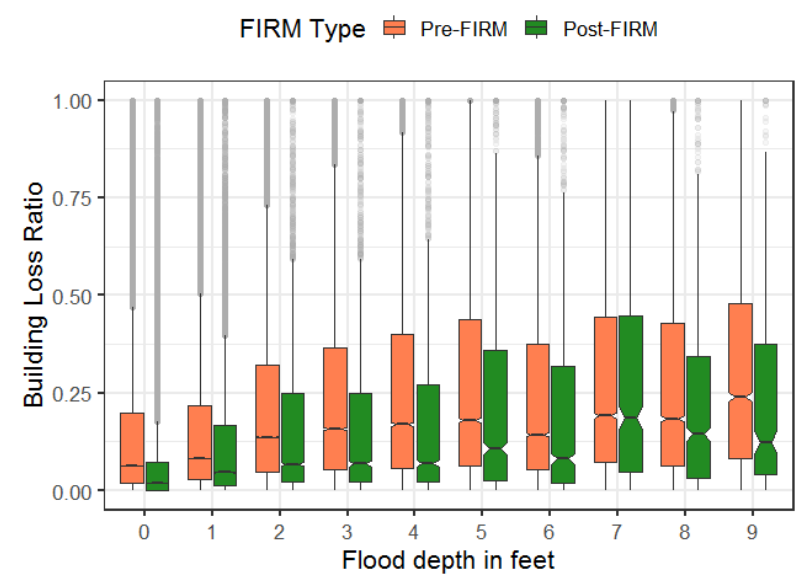

Figure 14. Depth-loss ratio distribution of non-surge flood claims in A zone by FIRM construction

FIRM Type 追 Pre-FIRM Post-FIRM

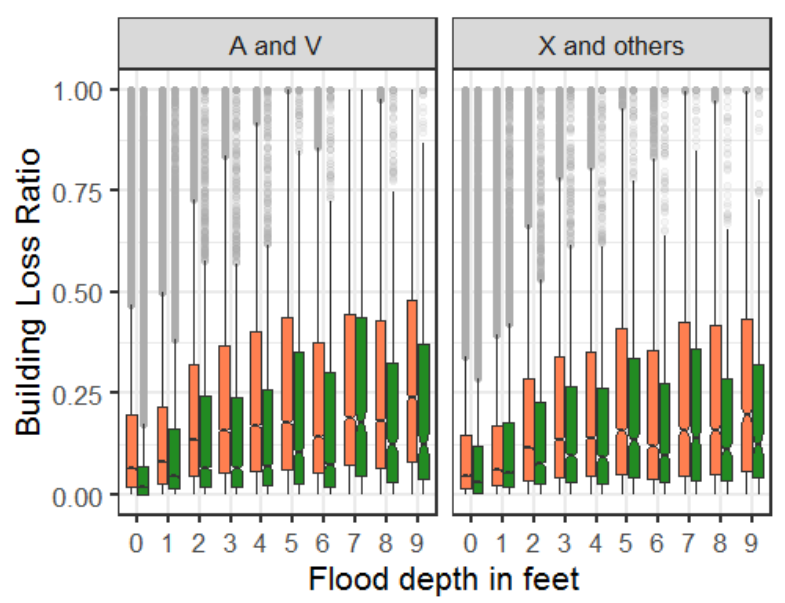

Figure 15. Depth-loss ratio distribution of non-surge flood claims by FIRM type and flood zone

While it is expected that post-FIRM construction buildings are more flood-resistant by way of design, the compliance of guidelines vary by flood zone. Outside the 100-year flood extent, in non-AV zones, post-FIRM 
buildings may continue to be built without the NFIP minimum elevation or other recommendations. Hence looking at depth to loss ratio distribution within the A zone as above might be insufficient. Figure 15 shows the impact of post-FIRM denomination on flood loss ratio within the 100-year flood extents (A and V zones) as well as outside the 100-year flood extent. The difference in loss ratios between pre-FIRM and post-FIRM in the non-AV zones is not as evident as the $\mathrm{A}$ and $\mathrm{V}$ zone, especially at lower depths where the building elevation may be helpful. As seen in Figure 6, generally A zone buildings are more vulnerable at higher depths than non-AV zones, resulting in seemingly lower loss ratio for both pre-FIRM and postFIRM buildings outside the 100-year flood extent. However, with the increase in flood risk outside the FEMA 100 -year flood extent, compliance of NFIP guidelines may be a prudent move for newer constructions.

\subsection{Presence of basement/enclosure}

Buildings with basements and enclosures where contents or equipment may be stored are more vulnerable to flooding than elevated buildings. NFIP dataset identifies if a building has basement or crawlspace below the first floor. The basement is further distinguished as finished and unfinished basement. Finished basements with fixtures, appliances and serving as liveable spaces may be more susceptible to flooding than unfinished basements. Figure 16 shows the depth to building loss ratio for buildings with different foundation type. Since NFIP claims contain flood depth as measured from the first floor above ground, the water depth in buildings with basement cause damage even at "negative" flood depths. Hence Figure 16 (a) shows the loss ratio comparison for positive depths from 0 to 10 feet and Figure 16 (b) shows the comparison from -4 feet to 4 feet.
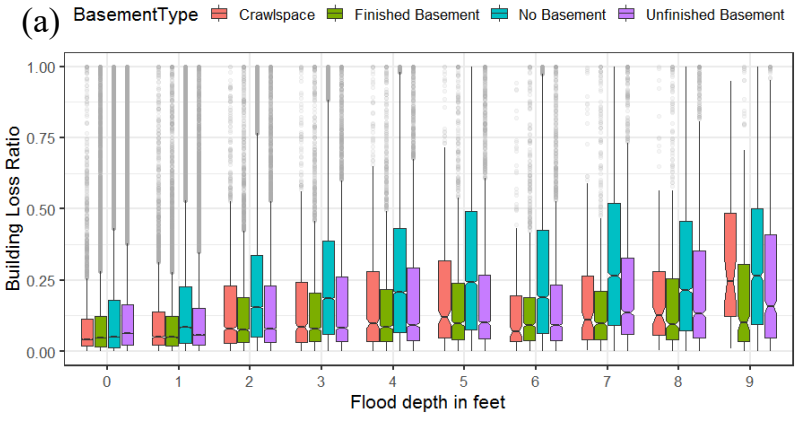

(b) BasementType 早 Crawispace 追 Finished Basement 追 No Basement 追 Unfinished Basement

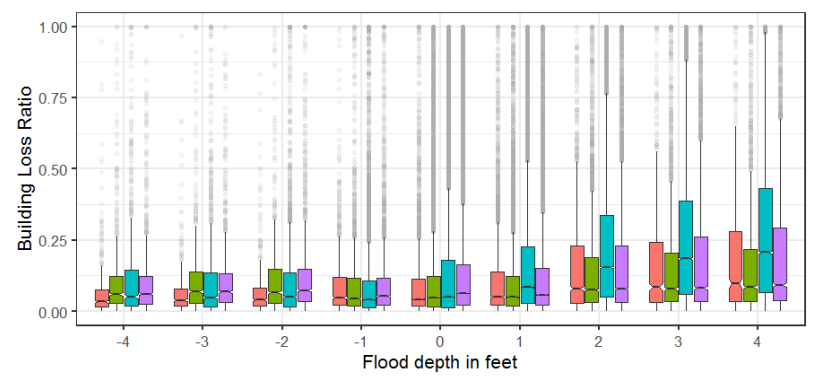

Figure 16. Depth-loss ratio distribution of non-surge flood claims in A zone by basement type: (a) From depth ranges of 0 feet to 10 feet (b) From depth range of -4 feet to 4 feet
Three key observations can be made from Figure 161) finished basements have higher loss ratio than unfinished basements, 2) no basement has higher loss ratio than all other cases and 3) claims with basements show low loss ratio even at negative depths. While the first observation follows logical sense, the second and third observations appear counter-intuitive. This trend is due to the fact that NFIP has limited flood insurance coverage for basement and as such the claims do not report the true flood losses in the basement in such buildings. This drastically alters the view of loss comparison and similar analysis of the basement "lowering" flood loss ratio is also noted by Kousky and Michel-Kerjan (2017). Buildings with crawlspace are more elevated than buildings on slab and hence the lower loss ratios at smaller flood depths in Figure 16 (a) is justified. Lowered average losses on crawlspace construction has also been noted by FEMA damage survey after Hurricane Harvey (FEMA, 2019b). As the flood depth increases, the loss ratios of buildings with crawlspace and buildings with no basement become similar, likely the cases when flooding breached the firstfloor level. This analysis highlights the need to understand the underlying data when performing such comparisons to avoid erroneous conclusions.

\subsection{Number of stories}

The number of stories data field in the NFIP claims dataset provides information the height of the building. In addition, this field also denotes if a building is a manufactured (or mobile) home and if the construction style is a split-level. Figure 17 shows the depth-loss ratio distribution by number of stories. As expected, as the number of stories increase, the median loss ratio decreases with one story building being most vulnerable to flooding. Split-level buildings mirror the behaviour of buildings with 3 or more stories as split levels usually have staggered floor levels, and often have 3 half-stories. Figure 17 also shows manufactured homes to be much more vulnerable than other buildings. The foundations of manufactured homes have proven to be vulnerable to floodwaters and noted in damage reports by FEMA (2009b) and stricter foundation anchoring has been recommended in newer manufacturing home installation guides (NFPA,2005).

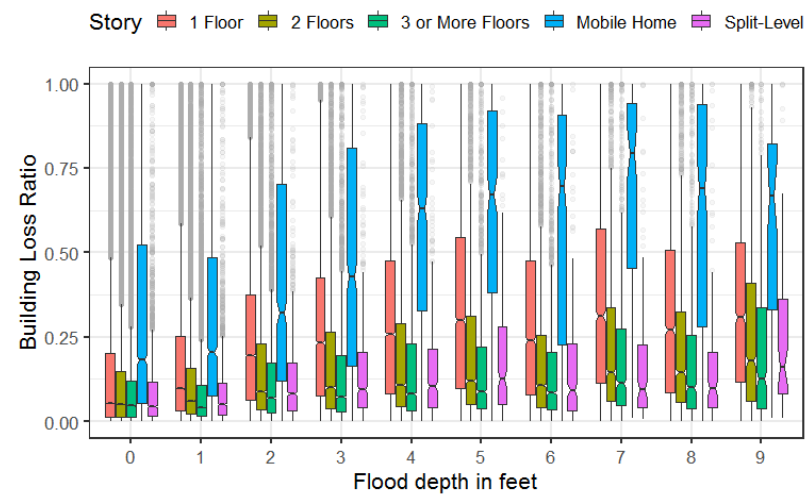

Figure 17. Depth-loss ratio distribution of non-surge flood claims in A zone by number of stories 


\section{Flood vulnerability of contents}

The two previous sections explored the impact of different hazard and building features on flood losses and flood damage potential for building losses. The building losses include the building envelope, utility equipment as well as permanent fixtures in a structure. While other studies have also analysed NFIP claims for building losses (Czajkowski et al. 2017, Kousky and Michel-Kerjan 2017, Wing et al. 2020), flood damage to the contents inside a building have been largely ignored. This is possibly due to the fact that the NFIP claims dataset has fewer claims with the replacement value for contents. The NFIP coverage for contents has to be bought separately from the building coverage and also is often paid out in terms of actual cash value, after considering depreciation of content value over time. However, the dataset has enough claims to do a few comparative analyses and explore influence of some parameters on content vulnerability to floods. Figure 18 shows the comparison of building and contents loss ratio distribution for NFIP claims; in each case, only claims with a valid replacement value is chosen. From the figure, it is clear that the content loss ratio distribution is wider, indicating higher flood vulnerability of contents when compared to building. (a)

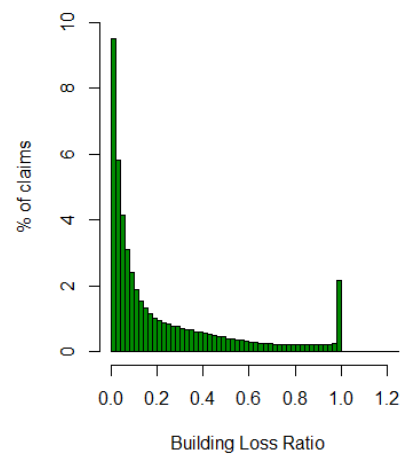

(b)

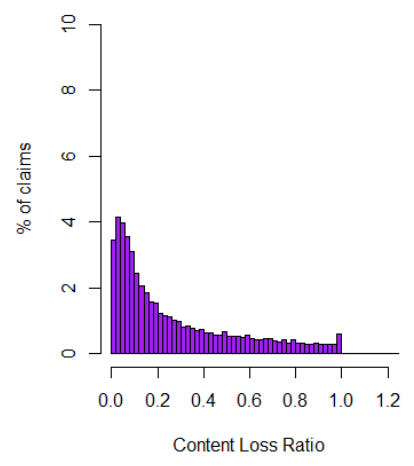

Figure 18. Loss ratio distribution of NFIP claims for (a) Building and (b) Content

For the depth to contents loss ratio, enough claims are not available to consider many parameters as the analysis in Section 3 and 4. The three main hazard and building features considered for the analysis in this section are- 1) type of flooding, 2) flood zone and FIRM type and 3) occupancy type. Unlike the influence of the type of flooding on building loss ratio (Figure 5), the content loss ratio does not vary as drastically due to type of flooding in Figure 19. Median content loss ratio for surge is indeed higher than inland or precipitation flooding, but this difference is mainly observed only at lower flood depths. In addition, the precipitation flooding has a larger median content loss ratio than inland flooding at most depths, possibly because most of the damage in precipitation flooding might be due to water entering the structure and not necessarily due to any building envelope failure.

The analysis in Section 3 and 4 concluded the variation of post-FIRM construction by flood zones $\mathrm{A}$ and $\mathrm{V}$ versus flood zone X. Figure 20 offers a comparative depth to content loss ratio by both these parameters. While the pre-
FIRM and post-FIRM loss ratios in A and V zone follow the same trend as building loss ratio (in Figure 15), in case of non-AV zones, the median loss ratio of contents of postFIRM buildings is equal or larger than pre-FIRM loss ratio. This is counterintuitive and could be attributed to the lesser compliance of NFIP guidelines outside the A and V zones, practically rendering newer buildings equally at flood risk as some of the older buildings or inadequacy of enough claims in the category to make such assumptions. However, similar observation on post-FIRM vs pre-FIRM loss ratio behaviour has been noted by Wing et al. (2020), albeit for total losses.

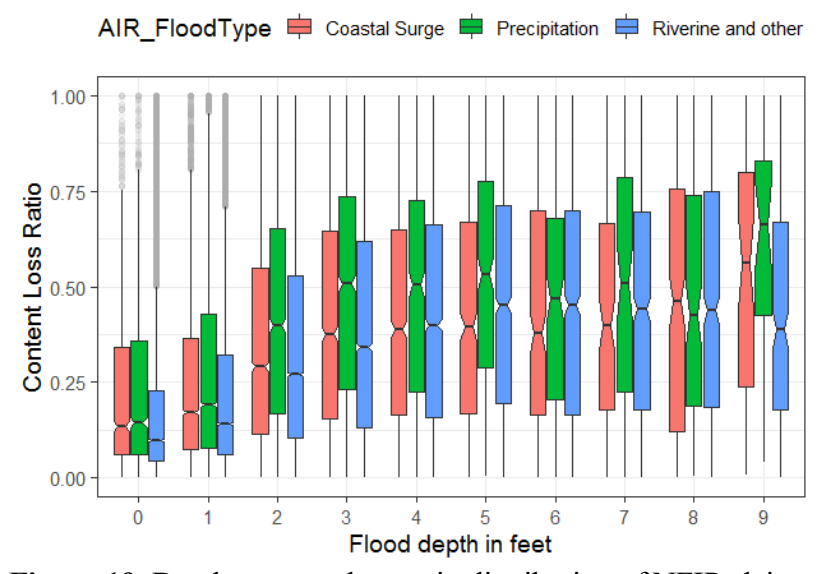

Figure 19. Depth- content loss ratio distribution of NFIP claims by AIR flooding type

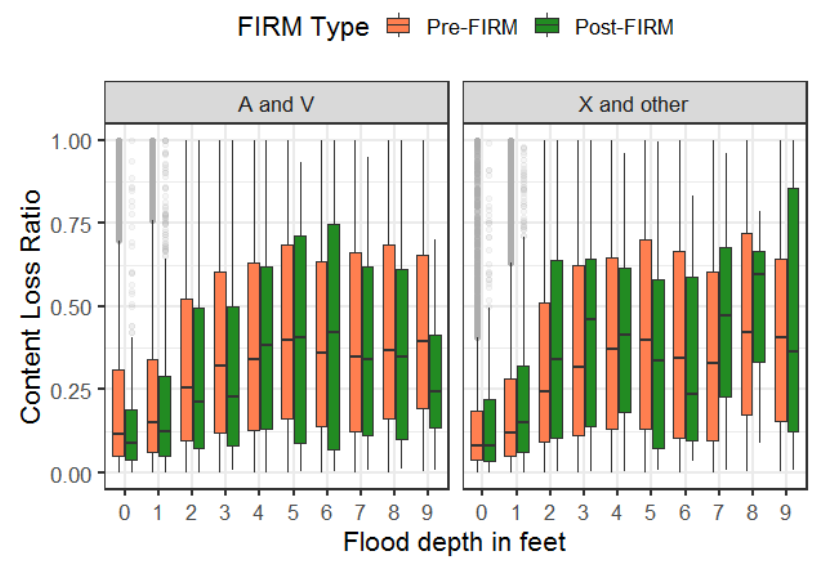

Figure 20. Depth- content loss ratio distribution of NFIP claims by FEMA flood zone and firm construction type

The last feature for comparison of contents loss ratio distribution is the occupancy or use of the building as shown in Figure 21. Only single-family homes and commercial properties are used for this comparison as the number of claims available for other categories are too few for any comparisons. Unlike building loss ratio in Figure 13, median loss ratio for commercial is higher than SFHs for content. This is mainly due to the fact that for SFHs, the building is more vulnerable, contributing to most of the flood damage. With commercial buildings, the building envelope is usually undamaged (because of higher engineering standards) and damage to contents loss is dominated by larger amount of very vulnerable stocked goods, electronics and movable equipment. 


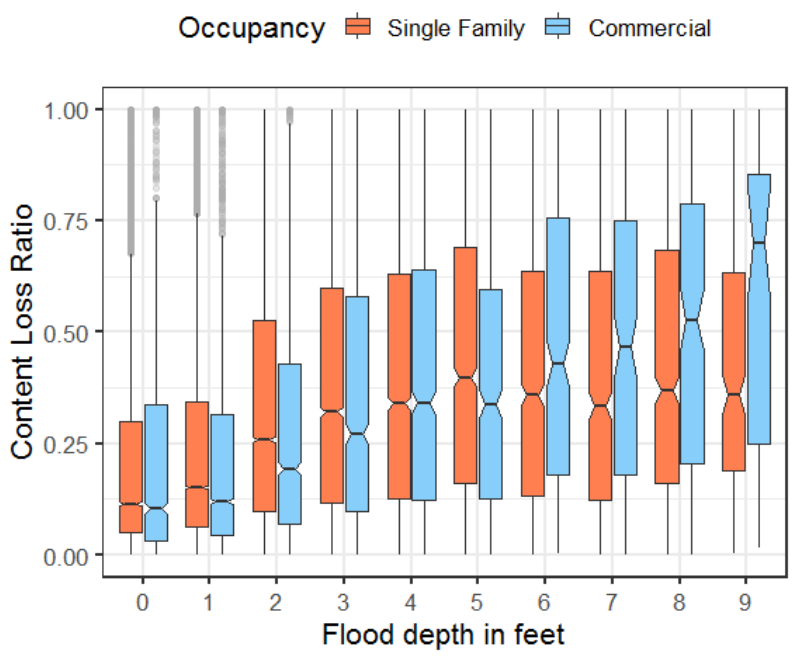

Figure 21. Depth- content loss ratio distribution of NFIP claims by building occupancy

\section{Results: summary and discussion}

The study presented in this paper evaluates NFIP flood claims in US to gain insights into influence of flood hazard and built environment features on flood resistance. The analysis is conducted based on both number of claims as well as looking at loss ratio (damage to replacement value) by different depth bins. Some of the challenges faced with using this data include possible errors in some data fields including replacement values or flood depths resulting in uncertainty around a median or mean loss ratio. Hence, the analysis relied on looking at a confidence interval around the median loss ratio to infer any conclusions.

The main factors impacting flood losses to both building and contents coverages include: 1) type of flooding, 2) occupancy of building, 3) flood zone and 4) NFIP compliance through post-FIRM construction guidelines. Median loss ratio due to surge driven flooding was relatively higher than both inland and precipitation driven flooding for building as well as contents, although the impact was more evident for building loss ratio. As for occupancy, single family homes (SFHs) seem more vulnerable than commercial buildings with respect to building loss, but less vulnerable than commercial for contents loss. This observation, while justified, might need more introspection as the NFIP claims dataset was heavily comprised of SFH claims. Both flood zone and post-FIRM compliance are correlated and influence both building and contents vulnerability. While flood zones $\mathrm{V}$ is more at flood risk than flood zones $\mathrm{A}$ and $\mathrm{X}$, the post-FIRM construction inside the $\mathrm{V}$ zones meet with the NFIP guidelines and have superior flood performance. Even though X, B and C zones are outside the FEMA 100-year flood extent, the number of claims inside these non-AV zones constitute around a third of total claims. In addition, the newer buildings outside the 100-year flood extent may not comply with NFIP guidelines, posing additional flood risk in the non-AV zones. The analysis here shows a need to re-evaluate flood mitigation practices inside the $\mathrm{X}, \mathrm{B}$ and $\mathrm{C}$ flood zones.
Apart from these features, this study also explored regional variation of building loss ratio due to flooding. This variation is in part due to type of flooding, but also due to enforcement of flood mitigation policies. For example, Florida has a stricter building code enforcement compared to other Gulf Coast states and this reflects in the lower loss ratio. The other insights gleaned from this study include increased flood vulnerability of manufactured homes as well as reduced flood vulnerability of crawlspace foundations. The presence of basement, while an important parameter for flood vulnerability, did not emerge as a predictor in flood damage. This is due to the nature of NFIP coverage of basement claims and highlights the need to not understand the data used for analysis.

The results from this study show that a depth-loss ratio relationship for predicting flood damage is suitable when additional secondary characteristics such as type of flooding, flood zone, occupancy, height etc. are considered. Understanding how these characteristics increase or decrease damage potential from flooding can be beneficial for multiple stakeholders, including risk management officials, insurers as well as modelers trying to assess the growing flood risk. Mitigation practices such as elevating buildings and moving service equipment as recommended by NFIP guidelines may need to be made mandatory for all newer construction, irrespective of flood zone. The publication of NFIP data also can foster conversation around repetitive flooding of high-risk zones and contribute to awareness of flood risk. This study, in addition to other NFIP claim analysis can enrich our knowledge and understanding of how the buildings resist and react to flooding.

\section{Reference}

1. AIR Worldwide (2020a). Managing U.S. flood risk: Part III, AIR's precipitation-induced flood vulnerability framework. Available at: AIR currents.

2. AIR Worldwide (2020b). Modeling fundamentals: evaluating US flood model loss output with historical loss experience. Available at: https://www.airworldwide.com/publications/aircurrents/2020/modeling-fundamentals-evaluating-u-s-flood-model-loss-output-with-historical-lossexperience/

3. ASCE/SEI (American Society of Civil Engineers/Structural Engineering Institute) (2015). Flood Resistant Design and Construction, ASCE/SEI Standard 24-14, ASCE, Reston, VA.

4. Blessing, R., A. Sebastian and S. D. Brody (2017). Flood risk delineation in the United States: How much loss are we capturing? Natural Hazards Review, 18(3), 04017002.

5. Brody, S. D., J. E. Kang and S. Bernhardt (2010). Identifying factors influencing flood mitigation at the local level in Texas and Florida: the role of organizational capacity. Natural hazards, 52(1), 167184. 
6. Brody, S. D., A. Sebastian, R. Blessing and P. B. Bedient (2018). Case study results from southeast Houston, Texas: identifying the impacts of residential location on flood risk and loss. Journal of Flood Risk Management, 11, S110-S120.

7. Czajkowski, J., H. Kunreuther and E. Michel-Kerjan (2012). A methodological approach for pricing flood insurance and evaluating loss reduction measures: Application to Texas. Risk Management and Decision Processes Center, the Wharton School, University of Pennsylvania.

8. Czajkowski, J., G. Villarini, M. Montgomery, E. Michel-Kerjan and R. Goska (2017). Assessing current and future freshwater flood risk from North Atlantic tropical cyclones via insurance claims. Scientific reports, 7(1), 1-10.

9. Federal Emergency Management Agency (2009a). Mitigation assessment team report: Hurricane Ike in Texas and Louisiana. Building Performance Observations, Recommendations, and Technical Guidance, FEMA P-757.

10. Federal Emergency Management Agency (2009b). Mitigation assessment team report: Midwest Floods of 2008 in Iowa and Wisconsin. Building Performance Observations, Recommendations, and Technical Guidance, FEMA P-765.

11. Federal Emergency Management Agency (2015). National Flood Insurance Program: Report to Congress on Reinsuring NFIP Insurance Risk and Options for Privatizing the NFIP. U.S. Department of Homeland Security. Retrieved from:

https://fedweb.com/wpcontent/uploads/2017/08/FEMAReinsuring NFIP Insurance Risk and Options for Privatizing the NFIP Report-Aug-13-2015.pdf

12. FEMA (2019a). FIMA NFIP Redacted Claims Data Set. Available at https://www.fema.gov/openfemadata-page/fima-nfip-redacted-claims-v1

13. Federal Emergency Management Agency (2019b). Mitigation assessment team report: Hurricane Harvey in Texas. Building Performance Observations, Recommendations, and Technical Guidance, FEMA P-2022.

14. Gradeci, K., N. Labonnote, E. Sivertsen and B. Time (2019). The use of insurance data in the analysis of Surface Water Flood events-A systematic review. Journal of Hydrology, 568, 194-206.

15. Jones, C. P., W. L. Coulbourne, J. Marshall and S. M. Rogers Jr (2006). Evaluation of the National Flood Insurance Program's building standards. American Institutes for Research, Washington DC, 1-118.

16. Kousky, C. and E. Michel-Kerjan (2017). Examining flood insurance claims in the United States: Six key findings. Journal of Risk and Insurance, 84(3), 819850.

17. Kriesel, W. and C. Landry. (2004). Participation in the National Flood Insurance Program: An empirical analysis for coastal properties. Journal of Risk and Insurance, 71(3), 405-420.

18. Moncoulon, D., D. Labat, J. Ardon, T. Onfroy, E. Leblois, C. Poulard, S. Aji, A. Rémy, and A. Quantin (2013). Analysis of the French insurance market exposure to floods: a stochastic model combining river overflow and surface runoff. Nat. Hazards Earth Syst. Sci 1, 3217-3261.

19. NFIP (2015) National Flood Insurance Program Transaction Record Reporting and Processing Plan Available at: https://nfipservices.floodsmart.gov/manuals/jan 2015 consolidated trrp.pdf

20. NFIP (2020) Summary of Coverage, National Flood Insurance Program. Available at: https://www.fema.gov/sites/default/files/202009/fema nfip-summary-coverage jul2020.pdf

21. NFPA (2009). Model Manufactured Home Installation Standard. NFPA 225. Available at: http://www.nfpa.org/ aboutthecodes/AboutTheCodes.asp?DocNum=225\&c ookie test $=1$

22. N.O.A.A (2020). Billion-Dollar Weather and Climate Disasters. National Center for Environmental Information, National Oceanic and Atmospheric Administration. Retrieved in December 2020 at: https://www.ncdc.noaa.gov/billions/events/US/20052020

23. Spekkers, M. H., M. Kok, F. H. L. R. Clemens and J. A. E. Ten Veldhuis (2014). Decision-tree analysis of factors influencing rainfall-related building structure and content damage. Natural Hazards and Earth System Sciences, 14(9), 2531.

24. Tonn, G., and J. Czajkowski (2018) An analysis of US tropical cyclone flood insurance claim losses: Storm surge vs. freshwater. Risk Management and Decision Processes Center, The Wharton School, University of Pennsylvania.

25. Wing, O. E., N. Pinter, P. D. Bates and C. Kousky (2020). New insights into US flood vulnerability revealed from flood insurance big data. Nature communications, 11(1), 1-10. 